\title{
Correction to: Mapping Public Concerns About Class Immobility in China
}

\author{
Shuanglong $\mathrm{Li}^{1} \cdot$ Yunsong Chen ${ }^{2,3}$ (D) Guangye $\mathrm{He}^{3}$ \\ Published online: 9 November 2019 \\ (c) Springer Nature B.V. 2019
}

\section{Correction to: Social Indicators Research (2019) 144:745-765 https://doi.org/10.1007/s11205-019-02075-2}

In the original publication of this article, the acknowledgement section has been missed to publish. Now the same has been provided in this correction.

Acknowledgements This study is supported by the Chinese National Social Science Funding Project "Determinants and Dynamics of Social Class Identification Among the Chinese in the Transitioning Period" (No. 16BSH011).

Publisher's Note Springer Nature remains neutral with regard to jurisdictional claims in published maps and institutional affiliations.

The original article can be found online at https://doi.org/10.1007/s11205-019-02075-2.

Yunsong Chen

yunsong.chen@nju.edu.cn

$\triangle$ Guangye He

hgy.gloria@nju.edu.cn

1 Department of Sociology, School of Public Administration, Guangzhou University, Guangzhou 510006, Guangdong, People's Republic of China

2 Hopkins-Nanjing Center, Nanjing University, 162 Shanghai Road, Nanjing 210008, Jiangsu, People's Republic of China

3 Department of Sociology, School of Social and Behavioral Sciences, Nanjing University, 163 Xianlin Road, Qixia District, Nanjing 210023, Jiangsu, People's Republic of China 